Journal of Social Sciences 8 (3): 364-371, 2012

ISSN 1549-3652

(C) 2012 Science Publications

\title{
Mobile Phone and Short Message Service Appropriation, Usage and Behavioral Issues among University Students
}

\author{
${ }^{1}$ Vimala Balakrishnan and ${ }^{2}$ Huck-Soo Loo \\ ${ }^{1}$ Faculty of Computer Science and Information Technology, \\ University of Malaya, 50603 Kuala Lumpur, Malaysia \\ ${ }^{2}$ Faculty of Mechanical Engineering, \\ Universiti Teknologi MARA (UiTM), 40450 Shah Alam, Malaysia
}

\begin{abstract}
Problem statement: This study aims to explore mobile phone and Short Message Service (SMS) usage among urbanized Malaysian youth. Uses and Gratification theory was used to explore mobile phone purchasing factors, reasons to use mobile phone and SMS, usage pattern and behavioral issues related to mobile phone and SMS. Structured questionnaire surveys and $24 \mathrm{~h}$ diaries were distributed to 417 students. Results show respondents consider brand, trend and price to be the three most important purchasing factors while socializing and privacy are the two most important reasons to use mobile phones. SMS is mostly used to organize social appointments and to keep in touch with families and friends. Behavioral issues related to over-dependence and inappropriate use of mobile phones and SMS were also observed among the respondents. Conclusion/Recommendations: The findings of this study could be beneficial to those exploring mobile phone and SMS adoption and usage pattern in a developing country such as Malaysia.
\end{abstract}

Key words: Mobile phone, short message service, questionnaire, 24-hour diary, uses and gratification theory

\section{INTRODUCTION}

The mobile phone is a multipurpose communication tool, an instrument used for phone calls, text messaging, on-line services, games and much more. This was due to the astonishing technological advancement from the first Generation (1G) to fourth $(4 \mathrm{G})$. It is not surprising that the number of mobile phones have outnumbered landline telephones in many countries, Malaysia included.

Short Messaging Service (SMS) is known to be the most popular application for mobile phones. SMS allows users to send brief messages to other mobile phones. Mobile phones and SMS are hugely popular amongst its users, especially the younger generation. Mobile phones increase social inclusion and connectedness and reinforce relationships between close friends and families (Srivastava, 2005; Geser, 2006). In addition it also provides a sense of security and safety as the youth can contact others in times of distress (Carroll et al., 2002). Mobile phones are also viewed as an extension of users' physical selves (Brown et al., 2002) and a crucial part of one's identity that many people claim they could not live without (Ito et al., 2005). They are also seen as an indicator of social status and power among teenagers (Ling and Pederson, 2005 ) and don't mention as a fashion item (Fortunati et $a l ., 2003)$ and a symbolic artifact of personal display (Fortunati et al., 2003).

Literature also revealed problems related to mobile phone users and the environment. Classrooms are being disrupted (Selwyn, 2003) and mobile phone use when driving increases accident risk (Pennay, 2004). Moreover, addiction or over dependency has also been reported, causing emotional stress, damaged relationships and falling literacy (Drennan and James, 2005).

Studies around the globe have reported various differences in the use of mobile phone and SMS. Japanese adolescents were found to keep their mobile phones on even when they are sleeping, indicating a sign of over dependency. The Japanese also do not seem to tolerate talking loudly into their phones whereas the Chinese do (Campbell, 2007). Japanese users were also found to be sensitive to the amount of time that passes after a message is sent (Ito et al., 2005). This is similar with respondents from the UK (Haddon, 2002), Italy (Spagnolli and Gamberini, 2007)

Corresponding Author: Huck-Soo Loo, Faculty of Mechanical Engineering, Universiti Teknologi MARA (UiTM), 40450 Shah Alam, Malaysia 


\section{J. Social Sci., 8 (3): 364-371, 2012}

and Denmark (Harper et al., 2005) who expect immediate replies to their messages.

Though work on mobile phone and SMS has been extensively studied in many countries, however the Malaysian youth cohort's appropriation and use of this medium is still under researched. This study aims to bridge this gap by particularly examining urbanized young Malaysians motivations for using mobile phones and SMS and behavioral issues related to the use of this medium, among others. Our results will be compared with literature work around the world in order to find similarities and/or differences between our respondents and youth elsewhere.

Mobile phone and SMS in Malaysia: The total number of mobile phone subscribers in Malaysia is approximately 34.5 million with a penetration rate of around $121 \%$ due to multiple subscriptions (MCMC, 2010). The introduction of pre-paid system increased the popularity of the mobile phones, particularly among young subscribers, who account for more than $30 \%$ of the total mobile phone subscribers in Malaysia. The majority of Malaysians $(79.4 \%)$ is pre-paid users while the rest $(20.6 \%)$ use post-paid (MCMC, 2010). The number of SMS users in Malaysia is also increasing. Studies by MCMC (2007) showed that there were approximately 9.9 billion SMS users in 2006, a number that shot to 14.7 billion in 2007.

Studies examining the mobile phone adoption and its usage among Malaysians are not many. For instance, Karim et al. (2006) explored the utilization of mobile phones in the educational environment, specifically in library and information services whereas Shaffril et al. (2009) assessed the potential use of mobile phones in the agricultural environment. As for SMS studies, Balakrishnan (2009) interviewed 110 Malaysian youth to analyze the overall pattern of SMS usage, however, the study only took factors such as frequency of SMS usage, number of SMS sent and received and frequency of using abbreviations, among others.

Due to the lack of research assessing mobile phone and SMS appropriation and its usage among Malaysians, this study aims to find:

1. The mobile phone and SMS usage pattern among the urbanized Malaysian youth,

2. Motivations to use mobile phone and SMS

3. Mobile phone purchasing factors,

4. Behavioral issues (if any) due to mobile phone and SMS use

It is to note that due to space limitation, results from the 24-hour diary that are related to the content of SMS and SMS language analysis are not presented here.
Theory conception and literature review:

Uses and gratification theory: According to Blumler and Katz (1974), Uses and Gratification (U\&G) theory is used to explain the motivations to use technologies, especially why consumers use media to satisfy their social and psychological needs. U\&G theory focuses on three main objectives: (i) to explain how individuals use media to gratify their needs, (ii) discover underlying motives for individuals' media use and (iii) to identify the positive and the negative consequences of individual media use. Various studies have applied this theory and a general conclusion is that "the gratifications sought motivate the use of a particular medium in an audience" (Leung, 2007).

$\mathrm{U} \& \mathrm{G}$ theory has been applied to examine the consumers' motives for using social networking sites (Urista et al., 2009) and mobile phones (Leung and Wei, 2001; Leung, 2007). Leung (2007) found sociability, instrumentality, reassurance, entertainment, acquisition and time management to be the gratifications to use mobile phones, other than affection/sociability, entertainment, instrumentality, psychological reassurance, fashion/status, mobility and immediate access (Leung and Wei, 2001). Most work on mobile phone usage gratifications were also carried out among the youth, especially college students (Auter, 2007; Sanders, 2008). The following section explores mobile phone and SMS usage among this particular cohort, particularly emphasizing on the usage pattern and also U\&G motivations.

Mobile phone usage and youth: Dresler-Hawke and Mansvelt (2008) explored the appropriation of mobile phone usage among 111 university students (18-24 years) in New Zealand. Their findings indicate that mobile phone is an extension of self, with the majority of their respondents leaving their phone on continually. The authors also suggest that mobile phones occupy an integral place in young people's lives and as a necessary part of social communication through the maintenance of key social networks.

Studies have also suggested that mobile phone is a medium of social capital, used to manage daily communications, that can be categorized as instrumental and intrinsic (Dimmick et al., 1994). Instrumental communication refers to the use of mobile phone to accomplish a task, such as, making appointments whilst intrinsic communication is done for the purpose of companionship or reassurance. Similarly, Tamminen et al. (2004) identified three motivational needs for using mobile phones, which include personal needs (privacy and security), navigation needs (as a form of way finding) and 


\section{J. Social Sci., 8 (3): 364-371, 2012}

social needs (awareness of changes in schedules and social activities).

Style is considered to be important when purchasing a mobile phone. Mobile phone project information on the user's style and how the user wants other people to see him/her (Ling and Pederson, 2005). Aoki and Downes (2003) reported their respondents purchase a mobile phone for safety, cost effectiveness, instant information access, social interaction with friends and family and privacy.

Studies have also reported problems due to excessive use of mobile phones among younger users, which include being in debt (Drennan and James, 2005), using mobile phones while driving (Pennay, 2004) and using mobile phones inappropriately in public places such as cinemas and classrooms, among others. Mobile phone users were also found to exhibit over-dependence towards their mobile phones, eventually causing other problems such as damaged relationships, emotional stress and loss of sleep, among others (Drennan and James, 2005).

SMS usage and youth: The SMS is also often used as a social communication tool, used to build new relationships, bond closely with families and friends, maintain and reinforce a strong sense of connection with peers (Ishii, 2006) in Japan, (Kim et al., 2007) Korea, (Harper et al., 2005) Norway and (Spagnolli and Gamberini, 2007) in Italy. SMS appears to be lightweight, inexpensive, less intrusive and enables easy contact with a distributed peer group. The privacy afforded by SMS also enables young people to communicate freely and discreetly, allowing them to create their own communities, thus excluding the adults in their lives and others outside their privileged circle (Harper et al., 2005; Thompson and Cupples, 2008). Furthermore, SMS is deemed to be fun, hence making it more attractive to the youth (Grant and O’Donohoe, 2007).

SMS has emotional significance and can be used to recall past thoughts and feelings (Taylor and Harper, 2003). When senders attempt to recall memories through sending SMS messages, it resembles a symbolic meaning to strengthen the relationship between the sender and recipient. The young users also prefer to exchange interesting mobile phone content, like jokes, among friends. As a matter of fact, $89 \%$ of young people in the Philippines were found to use SMS for such purposes.

SMS over-dependency has been reported by several studies as well. For example, some users tend to be obsessive about receiving and sending messages to avoid peer rejections, excessively using SMS and compulsively using SMS to build and maintain relationships (Igarashi et al., 2008). Furthermore, users were also reported to be sensitive to the amount of time that passes after a message is sent, to the point that they would send another text message or even call the recipients if messages are not replied immediately (Ito et al., 2005) in Japan and (Haddon, 2002) UK. However, this is in contrast with the American users who do not necessarily expect a reply when a message is sent (Brown et al., 2002).

\section{MATERIALS AND METHODS}

Theoretical framework: Based on the literature reviews, a theoretical framework was devised as depicted in Fig. 1. Four main factors were considered in this study, namely, motivations to use mobile phone and SMS, usage pattern, behavioral issues and also mobile phone purchasing factors. Relevant questions and statements were formulated into a structured questionnaire, as described below.

Questionnaire: A 67-item questionnaire assessing demographic information, frequency of mobile phone use, purchasing factors, frequency of SMS use, motivations to use SMS was prepared in English. Five university students reviewed the questionnaire and diary to gauge if survey respondents would be able to understand the questions, statements and instructions given in the research instruments. The final questionnaire revealed a Cronbach value of 0.89 indicating a high level of internal consistency.

The questionnaire consisted of two major sections. Section A focused on mobile phone and it is further divided into two more sub-sections as follows:

- Demographics: Respondents indicated their age, gender, state of origin, mobile phone payment method.

- Mobile phone usage: Respondents indicated the average number of calls made and received in a day, the most used application on their mobile phone.

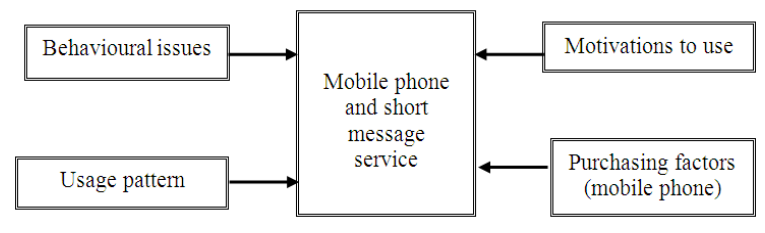

Fig. 1: Theoretical Framework 


\section{J. Social Sci., 8 (3): 364-371, 2012}

In addition, this section also consisted of statements requiring the respondents to state their agreement and/or disagreement levels based on a 5point Likert scale $(1=$ strong disagreement and $5=$ strong agreement). There were a total of 22 statements and they can be grouped as follows:

- Purchasing factors: Brand, trend, price.

- Motivations to use mobile phone: Statements include to socialize, need privacy and to gossip, among others.

- Behavior: Statements related to the psychological behavior, e.g., Addicted to mobile phone, if the respondents switch off their phones, if they check their phones constantly for missed calls.

Section B on the other hand, relates to SMS, containing questions such as years of using SMS, frequency of using SMS and the language used to compose messages, among others. Moreover, it also contained statements requiring the respondents to state their agreement and/or disagreement levels based on a 5-point Likert scale as above. There were a total of 29 statements, categorized as motivations to use SMS and also behavioral.

Motivations to use SMS: Statements such as SMS is fun, cheap, offers privacy and convenient, among others.

Behavior: Statements related to behavioral issues such as constantly checking the phone for messages, reading and replying messages immediately and getting distressed when no messages received in a day, among others.

Hour diary: Respondents were also asked to maintain a simple mobile phone communication diary for 24 hours. The diary was categorized into audio calls and SMS. For audio calls, the respondents were asked to record calls made and received, the person who called or was contacted, estimated duration of the call and also the purpose of the call. As for SMS, the respondents were required to record the number of messages sent and received, the sender and the recipient of the messages and also the content of the message in verbatim.

Respondents: Students are an ideal target to examine youth's perception as they fall within the age group of 17-30, the largest segment of mobile phone and SMS users (DeBaillon and Rockwell, 2005). In addition, the access to mobile phones and the likelihood of SMS usage among the students are high. Therefore, convenience sampling was used to seek respondents from local universities in Kuala Lumpur, Selangor and Melaka (three states with high mobile phone subscribers). These students are from all over the country; therefore, the diversity of the respondents' origins reflects the representativeness of the samples in this study. Most of the students would have left their hometowns to pursue their studies in the city; hence, we refer to them as urbanized youth. The questionnaires and diaries were distributed to 576 university students, undergraduates and post-graduates (294 in Selangor, 187 in Kuala Lumpur and 95 in Melaka). Of these, 417 were fully completed and returned (216 in Selangor, 113 in Kuala Lumpur and 88 in Melaka). The students were from the academic years of 2008-2010.

\section{RESULTS}

Statistical Package for the Social Sciences (SPSS) 19.0 was used to analyze the data. Descriptive statistics such as mean and standard deviations were used to analyze the data.

Demographics: There were a total of 417 respondents, comprising of 183 males and 234 females $(M=20.5$ years old, $\mathrm{SD}=1.31)$. The average years of experience in using a mobile phone and SMS was $4.3(\mathrm{SD}=0.94)$ and $5.1(\mathrm{SD}=0.67)$ respectively. Almost $95.7 \%$ of the respondents were pre-paid users and the remaining $4.3 \%$ were post-paid users. Nokia was the most favored brand with $72.5 \%$ of ownership, followed by Siemens $(11.4 \%)$, Ericsson $(8.7 \%)$, HTC $(4.3 \%)$ and Motorola $(3.1 \%)$.

Mobile phone and SMS usage pattern: Table 1 shows the majority number of calls and SMS made and received in a day. It was found that most respondents made and received between 1-5 calls per day. Diary analyses revealed the majority of the calls (96.3\%) were made to close friends and families. Similarly, most calls received $(88.1 \%)$ were from close friends and families as well. In addition, diary analyses also showed that most calls were made to make, confirm and cancel appointments related to studies and social activities $(54.5 \%)$, gossip $(23.7 \%)$, maintain social network (18.3\%) and others (e.g. Calling for a cab, fast food delivery).

As for SMS, $89.7 \%$ of the respondents sent between 6-10 messages daily and $92.3 \%$ received between 6-10 messages daily too. Similar to audio calls, friends $(98.1 \%)$ and family members (58.6\%) constituted the main two sets of people with whom the respondents communicated regularly using SMS. 


\section{J. Social Sci., 8 (3): 364-371, 2012}

Table 1: Mobile phone and SMS usage

\begin{tabular}{|c|c|c|c|}
\hline $\begin{array}{l}\text { Items } \\
\text { diary }\end{array}$ & $\begin{array}{l}\text { Frequency* } \\
(\%)\end{array}$ & Mean from & the \\
\hline \# of calls made daily & $1-5(94 \%)$ & & 3.8 \\
\hline \# of calls received daily & $1-5(64 \%)$ & & 4.1 \\
\hline \# of SMS sent daily & $6-10(89.70 \%)$ & & 8.9 \\
\hline \# of SMS received daily & $6-10(92.3 \%)$ & & 6.8 \\
\hline
\end{tabular}

Table 2: Purchasing factors ordered in the rank of descending mean values

\begin{tabular}{lcc}
\hline Statements & Mean & SD \\
\hline When purchasing a phone, one of & & \\
The important factor is: & & \\
Trend (qwerty keypad, touch-screen) & 4.27 & 0.708 \\
Brand (Nokia, iPhone) & 4.16 & 0.630 \\
Price & 4.12 & 0.568 \\
Aesthetic values (look, color) & 3.96 & 0.780 \\
Usability (ease of use, comfortable to hold) & 3.86 & 0.819 \\
\hline
\end{tabular}

Table 3: Motivations to use mobile phones ordered in the rank of descending mean values

\begin{tabular}{lll}
\hline Statements & Mean & SD \\
\hline My mobile phone is for: & & \\
Socializing & 4.16 & 0.422 \\
My privacy & 4.06 & 0.568 \\
As a status symbol. & 3.99 & 0.586 \\
My safety & 3.67 & 0.938 \\
\hline
\end{tabular}

Table 4: Motivations to use SMS ordered in the rank of descending mean values

\begin{tabular}{llc}
\hline Statements & Mean & SD \\
\hline I use SMS & & \\
To make/cancel appointments & 4.30 & 0.469 \\
Because it offers privacy & 4.27 & 0.453 \\
To gossip & 4.24 & 0.437 \\
To maintain relationships & 4.24 & 0.436 \\
It is cheap & 4.24 & 0.430 \\
It is easy to use & 4.23 & 0.471 \\
It is quick & 4.22 & 0.408 \\
It is convenient & 4.19 & 0.408 \\
To show people that I care about them & 4.18 & 0.428 \\
It is fun & 4.18 & 0.419 \\
It is stylish & 4.09 & 0.525 \\
To keep it as a memento & 4.08 & 0.518 \\
To make new friends & 4.05 & 0.569 \\
To avoid talking to someone & 3.98 & 0.677 \\
To flirt with someone & 3.89 & 0.710 \\
\hline
\end{tabular}

The majority of the respondents were found to use English $(56.8 \%)$, followed by Bahasa Malaysia (26.2\%), a combination of English and Bahasa Malaysia (11.6\%), English and Chinese (4.9) and English and Tamil (0.5\%) when they use SMS.

Purchasing factors: Table 2 below shows that most respondents emphasized more on trend, brand and price when it comes to purchasing a mobile phone. Aesthetic and usability factors, however, were not considered to be important judging from the low mean values (lower than 4.00).
Table 5: Mobile phone behavior related items ordered in the rank of descending mean value

\begin{tabular}{|c|c|c|}
\hline Statements & Mean & SD \\
\hline I feel distressed when my phone is not with me & 4.30 & 0.540 \\
\hline I never switch off my phone & 4. 27 & 0.536 \\
\hline I am addicted to my mobile phone & 4. 20 & 0.538 \\
\hline I always check for missed calls or messages & 4. 19 & 0.533 \\
\hline $\begin{array}{l}\text { I feel distressed when } \\
\text { someone doesn't return my call }\end{array}$ & 4. 18 & 0.489 \\
\hline $\begin{array}{l}\text { I feel distressed when someone } \\
\text { doesn't answer my call }\end{array}$ & 4. 12 & 0.474 \\
\hline $\begin{array}{l}\text { I only switch off my phone when } \\
\text { the need arises (lecture, cinema) }\end{array}$ & 3.90 & 0.733 \\
\hline $\begin{array}{l}\text { I only switch off my phone when I } \\
\text { do not want to be disturbed (studying) }\end{array}$ & 3.90 & 0.733 \\
\hline $\begin{array}{l}\text { I talk loudly into the phone } \\
\text { even when I am in public }\end{array}$ & 3.69 & 0.898 \\
\hline $\begin{array}{l}\text { I get annoyed when others } \\
\text { make/receive calls in class }\end{array}$ & 3.67 & 0.778 \\
\hline I make or receive calls when I am in a class & 2. 98 & 0.870 \\
\hline $\begin{array}{l}\text { I make/answer calls when } \\
\text { I am driving or riding a bik }\end{array}$ & 2.73 & 0.686 \\
\hline $\begin{array}{l}\text { I have been in debt due to } \\
\text { excessive use of mobile phone }\end{array}$ & 2.28 & 0.525 \\
\hline
\end{tabular}

Motivations to use mobile phone: As indicated by the high mean values in Table 3 below, socializing and privacy emerged as the two main reasons for using a mobile phone, closely followed by status symbol and safety purposes.

Motivations to use SMS: Table 4 shows that some of the main reasons to use SMS is to make/cancel appointments, gossip and maintain relationship, other than using it as it provides privacy, cheap, easy to use and quick. Only two items had mean values lower than 4.00 , that is, using SMS to avoid talking to someone and also to flirt with someone.

Behavioral issues: High means values in Table 5 and 6 (more than 4.00) show that respondents exhibit some over-dependence towards their mobile phone and SMS application. Other than feeling distressed when their phones are not with them, they also get distressed when someone does not answer or return their calls. Mean values lower than 3.00 indicate that the majority of the respondents do not make/receive calls during class and while driving/riding and have never been in debt due to excessive use of their mobile phones (Table 5).

As for behavioral issues related to SMS, respondents also indicated that they tend to spend a lot of time on SMS daily, use SMS in class; check messages even in the middle of a conversation and get disappointed if no messages are received in a day. Two items scored lower than 3.00 on behavioral issues, namely, going through their messages when they are lonely and getting annoyed when others use SMS in class. 


\section{J. Social Sci., 8 (3): 364-371, 2012}

Table 6: SMS behavioral issues ordered in the rank of descending mean values

\begin{tabular}{|c|c|c|}
\hline Statements & Mean & SD \\
\hline $\begin{array}{l}\text { I get distressed when someone doesn't } \\
\text { reply my message at all }\end{array}$ & 4.27 & 0.558 \\
\hline $\begin{array}{l}\text { I always read my received } \\
\text { messages immediately }\end{array}$ & 4. 26 & 0.530 \\
\hline $\begin{array}{l}\text { After sending a message, I constantly } \\
\text { check my phone for a reply }\end{array}$ & 4. 21 & 0.558 \\
\hline $\begin{array}{l}\text { I get distressed when someone doesn't } \\
\text { reply my message immediately }\end{array}$ & 4. 20 & 0.550 \\
\hline I always reply my messages immediately & 4. 17 & 0.536 \\
\hline I constantly check my phone for messages & 4. 16 & 0.497 \\
\hline $\begin{array}{l}\text { I often exchange many texts-messages in a } \\
\text { short period of time }\end{array}$ & 4. 14 & 0.447 \\
\hline I spend a lot of time on SMS daily & 4. 13 & 0.511 \\
\hline $\begin{array}{l}\text { I check my messages even when I am in } \\
\text { a middle of a conversation }\end{array}$ & 4. 13 & 0.532 \\
\hline I use the SMS in class & 4. 13 & 0.535 \\
\hline $\begin{array}{l}\text { I only reply my messages immediately } \\
\text { if it is urgent }\end{array}$ & 4. 12 & 0.520 \\
\hline $\begin{array}{l}\text { I get disappointed when I don't receive } \\
\text { any SMS in a day }\end{array}$ & 3.45 & 0.589 \\
\hline $\begin{array}{l}\text { I go through my messages when } \\
\text { I am free/lonely }\end{array}$ & 2. 86 & 0.546 \\
\hline I get annoyed when others use SMS in class & 2. 60 & 0.690 \\
\hline
\end{tabular}

\section{DISCUSSION}

The mobile phone has simplified communication and brought lots of benefits for many users, especially the youth worldwide. This study found similar mobile phone communication patterns among the respondents, for instance, there was a general consensus among the respondents for the reasons to use mobile phones, with the majority of them indicating socializing and for privacy purpose. This was further supported by the diary analysis that showed the majority of the calls were made to make, arrange and cancel appointments. Mobile phone enables the youth to improve their social network and to be able to contact the others easily and quickly despite the geographical or time constraints.

The three most important factors considered for mobile phone purchase were brand, trend and price. The mobile phone serves as a form of identity for younger users and the brand says a lot about the owner. In other words, it is simply fashionable to own a branded mobile phone. Surveys conducted among teenage Africans in UK (Ogunyemi, 2010) revealed preferences towards Nokia, Samsung and Motorola while in China the choice of brands was Nokia, Ericsson and Samsung (Wang, 2005), similar to our findings.

The respondents were found to use SMS mainly to manage appointments, followed closely by privacy, gossip and relationship maintenance. The youth are known to use SMS for coordinating their daily activities with their friends that include making plans to meet up for lunch or dinner and arranging schedules for discussions (Hagan and Rice, 2007), similar with users in Japan (Ishii, 2006), Norway (Harper et al., 2005) and Italy (Spagnolli and Gamberini, 2007). In addition, SMS is also favored as it is cheap, quick and easy to use.

Results also indicate that the majority of the respondents were over-dependent on their mobile phones, as they were found to identify with any behavioral issue such as regularly checking their phones for missed calls/messages throughout the day. In addition, the majority of the respondents also feels distressed when they do not have their phones with them further indicating their attachment to their phones. This concurs with Walsh et al. (2010) whose respondents reported feeling angry, frustrated and concerned when they were unable to use their phones, indicating a sense of loss without their phones. The symptom for the addiction can also be noted when the majority of the respondents admitted to never switching off their mobile phones. This is similar to MACRO (2004) finding in Mumbai, India, where 58\% of his respondents could not manage their lives without their mobile phones even for a day and $72 \%$ leave their phones on. Respondents in America (Rainie, 2006), UK (TCW, 2006) and New Zealand (Dresler-Hawke and Mansvelt, 2008) were also reported to being attached to their mobile phones.

Some respondents in this study claimed to turn off their phones at inappropriate times like when they are in the cinema. They also stated that they do not make/receive calls in class and they get annoyed when others do so. This concurs with a study done by Campbell (2006) among 176 college students and staff. His respondents reported negative attitudes about mobile phones in classrooms and regarded ringing during class a serious problem. On the contrary, the majority of the respondents in this study used SMS in class and they also do not get annoyed when others use SMS in class. This definitely has a negative impact on the learning abilities of the students, as they are not able to concentrate fully on their lecture.

It is also interesting to note that the youth's perception of the inappropriate mobile phone is not extended for talking loudly on the phone in public. A close mean value of 4.00 indicate that the majority of the respondents does not perceive talking loudly on their mobile phones is a problem, similar to the Chinese (Campbell, 2007). Other studies have reported bystanders to be offended and irritated with other people's mobile phone conversations and many even 
considered it inappropriate to talk on the mobile phone in a variety of settings, including restaurants, buses and theatres, among others (Ling, 1996).

There is also a consensus among our respondents towards SMS over-dependency. This can be noted from their tendencies to constantly check for messages, expecting reciprocity immediately and getting distressed when their messages are not replied (immediately), among others. Respondents from countries such as Japan (Igarashi et al., 2005), UK (Haddon, 2002), Italy (Spagnolli and Gamberini, 2007) and Denmark (Harper et al., 2005) were also found to exhibit such behavior.

\section{CONCLUSION}

A mixed-mode method consisting of structured questionnaires and 24-hours diaries were used to analyze the mobile phone and SMS usage patterns, motivations to use, mobile phone purchasing factor and behavioral issues related to the use of mobile phones and SMS among 417 urbanized Malaysian youth. The main findings indicate our respondents to consider brand, trend and price when purchasing mobile phones, similar to the youth worldwide. Most of the respondents were also found to use their mobile phones and SMS to socialize with their families and friends. As for the behavioral issues, the majority of the respondents were found to exhibit over-dependency towards mobile phone and SMS, with many constantly checking their phones for missed calls/messages, feeling distressed when they do not have their phones with them, replying messages immediately. The findings from this study are believed to serve as a knowledge base for other researchers who intend to explore mobile phone and SMS usage and other issues related to their usage among urbanized Malaysian youth.

\section{REFERENCES}

Aoki, K. and E.J. Downes, 2003. An analysis of young people's use of attitudes toward cell phones. Telematics Inform., 20: 349-364. DOI: 10.1016/S0736-5853(03)00018-2

Auter, P.J., 2007. Portable social groups: Willingness to communicate, interpersonal communication gratifications and cell phone use among young adults. Int. J. Mobile Commun., 5: 139-156.

Balakrishnan, V., 2009. A look into SMS usage patterns among Malaysian Youths. Hum. IT., 10: 55-80.

Blumler, J.G. and E. Katz, 1974. The Uses of Mass Communications: Current Perspectives on Gratifications Research. 1st Edn., Sage Publications, Beverly Hills, CA., pp: 318.
Brown, B., N. Green and R. Harper, 2002. Wireless World: Social and Interactional Aspects of the Mobile Age. 1st Edn., Springer, London, ISBN-10: 1852334770, pp: 229.

Campbell, S.W., 2006. Perceptions of mobile phones in college classrooms: Ringing, cheating and classroom policies. Commune. Educ., 55: 280-294. DOI: $10.1080 / 03634520600748573$

Campbell, S.W., 2007. A cross-cultural comparison of perceptions and uses of mobile telephony. New Media Soc., 9: 343-363. DOI: $10.1177 / 1461444807075016$

Carroll, J., S. Howard, J. Peck and J. Murphy, 2002. A field study of perceptions and use of mobile telephones by 16 to 22 year olds. J. Inform. Technol. Theory Pract., 4: 49-61.

DeBaillon, L. and P. Rockwell, 2005. Gender and student-status differences in cellular telephone use. Int. J. Mobile Commun., 3: 82-98.

Dimmick, J.W., J. Sikand and S.J. Patterson, 1994. The gratifications of the household telephone: Sociability, instrumentality and reassurance. Commune. Res., 21: 643-663. DOI: 10.1177/009365094021005005

Drennan, J. and D. James, 2005. Exploring addictive consumption of mobile phone technology. Proceedings of the Australian and New Zealand Marketing Academy Conference, Dec. 5-7, Australia, Western Australia, Fremantle.

Dresler-Hawke, E. and J. Mansvelt, 2008. Mobile phones: Enhancing social communication in young adult's lives? Massey University.

Fortunati, L., J.E. Katz and R. Riccini, 2003. Mediating the Human Body: Technology, Communication and Fashion. 1st Edn., Taylor and Francis, Mahwah NJ, ISBN-10: 0805844805, pp: 230.

Geser, H., 2006. Is the cell phone undermining the social order?: Understanding mobile technology from a sociological perspective. Knowl. Technol. Policy, 19: 8-18. DOI: 10.1007/s12130-006-1010-x

Grant, I. and S. O'Donohoe, 2007. Why young consumers are not open to mobile marketing communications. Int. J. Adv., 26: 223-246.

Haddon, L.G., 2002. Youth and mobiles: The British case and further questions. J. Youth Stud., 57: 115124.

Hagan, I. and R. Rice, 2007. Social connectivity, multitasking and social connectivity, multitasking and social control: U.S./Norwegian college students use of the internet and mobile phones. Proceedings of the Annual Meeting of the International Communication Association, May 2323, TBA, San Francisco, CA. 
Harper, R., L.A. Palen and A.S. Taylor, 2005. The Inside Text: Social, Cultural and Design Perspectives on SMS. 1st Edn., Springer, Dordrecht, ISBN-10: 1402030592, pp: 330.

Igarashi, T., J. Takai and T. Yoshida, 2005 Gender differences in social network development via mobile phone text messages: A longitudinal study. J. Soc. Personal Relationships, 22: 691-713. DOI: 10.1177/0265407505056492

Igarashi, T., T. Motoyoshi, J. Takai and T. Yoshida, 2008. No mobile, no life: Self-perception and textmessage dependency among Japanese High School Students. Comput. Hum. Behav., 24: 2311-2324. DOI: $10.1016 /$ j. chub. 2007.12.001

Ishii, K., 2006. Implications of mobility: The uses of personal communication media in everyday life. $\mathrm{J}$. Commune., 56: 346-365. DOI: 10.1111/j. 14602466.2006.00023. x

Ito, M., D. Okabe and M. Matsuda, 2005. Personal, Portable, Pedestrian: Mobile Phones in Japanese Life. 1st Edn., MIT Press, Cambridge, MA, ISBN10: 0262090392 , pp: 357.

Karim, N.S.A., S.H. Darus and R. Hussin, 2006. Mobile phone applications in academic library services: A students' feedback survey. Campus-Wide Inform. Syst., 23: 35-51.

Kim, H., G.J. Kim, H.W. Park and R.E. Rice, 2007. Configurations of relationships in different media: $\mathrm{FtF}$, email, instant messenger, mobile phone and SMS. J. Comput. Mediated Commun.

Leung, L. and R. Wei, 2001. More than just talk on the move: A use-and-gratification study of the cellular phone. Journalism Mass Commun. Q., 77: 308-320.

Leung, L., 2007. Unwillingness-to-communicate and college students' motives in SMS mobile messaging. Telematics Inform., 24: 115-129. DOI: 10.1016/j.tele.2006.01.002

Ling, R., 1996. "One Can Talk about Common Manners!": The Use of Mobile Telephones in Inappropriate Situations. 1st Edn., Telenor, Kjeller, ISBN-10: 8242304203, pp: 24.

Ling, R.S. and P.E. Pederson, 2005. Mobile communications: Re-negotiation of the social sphere. 1st Edn., Birkhauser, ISBN-10: 1852339314, pp: 454.

MACRO, 2004. A report on study of mobile phone usage among the teenagers and youth in Mumbai. Market Analysis and Consumer Research Organization.

MCMC, 2007. Communications and multimedia: Selected facts and figures. Malaysian Communications and Multimedia Commission.

MCMC, 2010. Facts and figures-statistics and records. Malaysian Communications and Multimedia Commission.
Ogunyemi, O., 2010. Consumption and (in) appropriate use of mobile phone among teenage Africans in the UK. University of Lincoln Brayford Pool, Lincoln.

Pennay, D., 2004 Community Attitudes to Road Safety: Community Attitudes Survey Wave. 1st Edn., Australian Transport Safety Bureau, Canberra, ISBN-10: 0642255237, pp: 118.

Rainie, L., 2006. PEW Internet project data memo. PEW Internet and American Life Project.

Sanders, W., 2008. Mobile phone usage among young, urban Chinese. Proceedings of the National Communication Association Conference on Communication and Mass Media Complete, Jun. 33, EBSCOhost, pp: 1-27.

Selwyn, N., 2003. Schooling the mobile generation: The future of schools in the mobile-networked society. Br. J. Educ., 24: 131-144.

Shaffril, M., H. Azril, Hassan, M. Salleh and Hassan et al., 2009. Agro-based industry, mobile phone and youth: A recipe for success. Eur. J. Sci. Res., 36: 41-48.

Spagnolli, A. and L. Gamberini, 2007. Interacting via SMS: Practices of social closeness and reciprocation. Br. J. Soc. Psychol., 46: 343-364. PMID: 17565786

Srivastava, L., 2005. Mobile phones and the evolution of social behavior. Behav. Inform. Technol., 24: 111-129. DOI: 10.1080/01449290512331321910

Tamminen, S., A. Oulasvirta, K. Toiskallio and A. Kankainen, 2004. Understanding mobile contexts. Personal Ubiquitous Comput., 8: 135-143. DOI: 10.1007/s00779-004-0263-1

Taylor, A.S. and R. Harper, 2003. The gift of the gab?: A design oriented sociology of young people's use of mobiles. Comput. Supported Cooperative Work, 12: 267-296. DOI: 10.1023/A:1025091532662

TCW, 2006. The mobile life report 2006: How mobile phones change the way we live. The Carphone Warehouse.

Thompson, L. and J. Cupples, 2008. Seen and not heard? Text messaging and digital sociality. Soc. Cultural Geography, 9: 95-108. DOI: 10.1080/14649360701789634

Urista, M.A., Q. Dong and K.D. Day, 2009. Explaining why young adults use MySpace and Facebook through the uses and gratifications theory. Hum. Commune., 12: 215-229.

Walsh, S.P., K.M. White and R.M. Young, 2010. Needing to connect: The effect of self and others on young people's involvement with their mobile phones. Australian J. Psychol., 62: 194-203. DOI: 10.1080/00049530903567229

Wang, J., 2005. Youth culture, music and cell phone branding in China. Global Media Commun., 1: 185-201. DOI: 10.1177/1742766505054633 